\title{
Hemodynamic defense response to thyrotropin-releasing hormone injected into medial preoptic nucleus in rats
}

\author{
ANNA-LEENA SIREN, STEFAN VONHOF, AND GIORA FEUERSTEIN \\ Department of Neurology, Uniformed Services University of the Health Sciences, \\ Bethesda, Maryland 20889-4799; and Department of Pharmacology, SmithKline \\ Beecham Laboratories, King of Prussia, Pennsylvania 19406-0939
}

\begin{abstract}
Siren, Anna-Leena, Stefan Vonhof, and Giora FeuerSTEIN. Hemodynamic defense response to thyrotropin-releasing hormone injected into medial preoptic nucleus in rats. Am. J. Physiol. 261 (Regulatory Integrative Comp. Physiol. 30): R305R312, 1991.- The role of thyrotropin-releasing hormone (TRH) and glutamate in central cardiovascular control was studied by microinjections $(50 \mathrm{nl})$ of these agents into the medial or median preoptic nuclei of conscious rats $(n=49)$ with continuous recording of mean arterial pressure, heart rate, blood flow, and vascular resistance in hindquarter, renal, and mesenteric blood vessels. In addition, the effect of TRH on renal sympathetic nerve activity was studied in anesthetized rats. TRH (2.4-240 pmol) elicited the typical hemodynamic pattern of the "defense response" consisting of increased blood pressure, tachycardia, hindquarter vasodilation, and constriction of renal and mesenteric blood vessels. Maximum changes in cardiovascular variables after the 24 -pmol dose were $+12 \pm$ $2 \mathrm{mmHg}$ (mean arterial pressure), $+73 \pm 15$ beats $/ \mathrm{min}$ (heart rate), $-21 \pm 6 \%$ (hindquarter resistance), $+15 \pm 6 \%$ (renal resistance), and $+31 \pm 6 \%$ (mesenteric resistance), $P<0.05$ compared with saline. In anesthetized rats, TRH at the 2.4pmol dose increased renal sympathetic nerve activity $(>200 \%$, $n=5, P<0.05$ compared with control) with no effect on blood pressure or renal flow. Glutamate $(10$ or $100 \mathrm{nmol})$ produced a similar pattern of hemodynamic changes as TRH. Peak effects after the $100-\mathrm{nmol}$ dose of glutamate were $+16 \pm 2 \mathrm{mmHg}$ (mean arterial pressure), $+57 \pm 11$ beats $/ \mathrm{min}$ (heart rate), -31 $\pm 3 \%$ (hindquarter resistance), $+29 \pm 9 \%$ (renal resistance), and $+87 \pm 22 \%$ (mesenteric resistance), $P<0.05$ compared with saline. The glutamate $N$-methyl-D-aspartate (NMDA) receptor blocker MK-801 (300 $\mu \mathrm{g} / \mathrm{kg}$ iv) attenuated the pressortachycardic responses to TRH and the pressor-mesenteric constrictor responses to glutamate. The results suggest that TRH and glutamate may be involved in the integration of hemodynamic and sympathetic responses to stress by a mechanism that at least in part involves the activation of glutamatergic NMDA receptors.
\end{abstract}

blood pressure; heart rate; vascular resistance; mesenteric blood flow; renal blood flow; hindquarter blood flow; plasma catecholamines; renal sympathetic nerve activity; brain microinjection; glutamate; $n$-methyl-D-aspartate receptors; MK-801

DIENCEPHALIC NUCLEI are critically involved in controlling defense responses during affective behavior $(28,30)$. The medial preoptic nucleus (POM), a paired structure along both sides of the third ventricle, receives extensive inputs from cardiovascular nuclei including the amygdala, paraventricular hypothalamic nucleus, the para- brachial nucleus, and the nucleus tractus solitarius (NTS) $(4,25)$. The principal projection of the POM descends through the medial forebrain bundle to the lateral hypothalamus and to the periaqueductal gray and medullary raphe and magnocellular reticular nuclei through which structures the POM is connected with the NTS and the preganglionic sympathetic neurons in the intermediolateral cell column (IML) of the spinal cord $(4,25)$. Electrical stimulation of the POM and median preoptic nucleus (POMn) produces a pattern of hemodynamic changes identical to the stress-evoked defense response including hindquarter vasodilation and renosplanchnic vasoconstriction $(2,8,28,30)$. Whether these responses are due solely to activation of neurons in the preoptic area is unclear since electrical current not only excites neurons in the stimulated area but also axons passing through the region. Thus the responses elicited by electrical stimulation can be due to mixed activation of local POM neurons and of axons of nuclei that are located far from the stimulation site.

Earlier studies have implied a role for thyrotropinreleasing hormone (TRH) in the hypothalamic control of blood pressure and heart rate $(5,7,24)$. Immunohistochemical and autoradiographic studies have demonstrated the presence of TRH, its precursor, and receptors in the POM $(19,22,23)$. Intracerebral injection of TRH into the POM area was further reported to increase blood pressure, heart rate, and plasma catecholamines in the conscious rat (7). More discrete microinjections of nanoliter volumes $(50-150)$ of $\mathrm{TRH}$ into the POM were shown to induce increases in blood pressure and heart rate in halothane-anesthetized rats $(5,24)$. However, the differential vascular and sympathetic responses to TRH were not monitored in any of the previous studies. In a previous study from our laboratory, intracerebroventricular (icv) administration of $\mathrm{TRH}$ in the conscious rat elicited the vasomotor defense response that was dependent on the intact function of sympathetic nerves and adrenal medulla (26). The present study therefore was designed to test whether the POM could be the site for the vasomotor defense response induced by icv administered TRH in the conscious rat. We used highly discrete microinjections in a small volume $(50 \mathrm{nl})$ that were confined within the POM with over $75 \%$ recovery (29). In addition, the TRH responses in the POM were compared with those induced by the excitatory amino acid L-glutamate and the potential TRH-glutamate in- 
teraction tested by treatment with the selective glutamate- $\mathrm{N}$-methyl-D-aspartate (NMDA)-receptor blocker (+)-5-methyl-10,11-dihydro-5H-dibenzo[a,d]cyclohepten-5, 10-imine (MK-801) (14).

\section{MATERIALS AND METHODS}

Male Sprague-Dawley rats (300-360 g) were purchased from Taconic Farms (Germantown, NY) and kept at $22^{\circ} \mathrm{C}$ and $12: 12 \mathrm{~h}$ light-dark cycle. After surgical operations the rats were housed individually in plastic cages $(21 \times 27 \times 16 \mathrm{~cm})$, with food and water ad libitum.

Intrahypothalamic injections. The rats were anesthetized with an intramuscular injection of ketamine (130 $\mathrm{mg} / \mathrm{kg})$ and acepromazine $(1.3 \mathrm{mg} / \mathrm{kg})$ and were placed on a stereotaxic device (DKI). A stainless steel guide cannula was inserted through the skull and fixed with glue (Eastman 910 adhesive). The injections into the POM were done by means of a premeasured 30 -gauge stainless steel cannula ( $9.5 \mathrm{~mm}$ length) inserted into the POM through the guide cannula 7 days after the implantation of the guide cannula. The injection cannula was connected via a polyethylene catheter to a $500 \mathrm{nl} \mathrm{Ham}$ ilton microsyringe, and a $50 \mathrm{nl}$ volume of the drug or saline solution was injected into the POM over $30 \mathrm{~s}$. On completion of the experiment, the rats were killed, and the brains were immediately removed, placed on a specimen holder, and rapidly frozen on dry ice. The brain was then cut $(50 \mu \mathrm{m})$ in a cryostat, and the dried sections were stained with thionine $(0.1 \%)$. The site of injection into the POM was microscopically confirmed according to the brain atlas of König and Klippel (15).

The spread of the intrahypothalamic injections was assessed by microinjections of $\left[{ }^{3} \mathrm{H}\right]\left[\left(3-\right.\right.$ methyl-His $\left.\left.^{2}\right)\right]-$ TRH (New England Nuclear, $55 \mathrm{Ci} / \mathrm{mmol}, 50 \mathrm{nl}$ of a 15 $\mu \mathrm{M}$ solution) into the POM. Two minutes after the injection the animals were killed, and the brains were immediately removed, placed on a specimen holder, and rapidly frozen on dry ice. The brains were then cut in a cryostat in the following way: $10 \mu \mathrm{m}$ for autoradiography, $50 \mu \mathrm{m}$ discarded, $50 \mu \mathrm{m}$ for counting of radioactivity, and $50 \mu \mathrm{m}$ for histology (see above).

Autoradiography. The microscope slides were placed after thorough drying together with tritium plastic standards ( ${ }^{3} \mathrm{H}$ microscales, Amersham) into X-ray cassettes and were exposed to tritium-sensitive film (Ultrofilm; LKB, Gaithersburg, MD) for 4 wk at $6-8^{\circ} \mathrm{C}$. After development in D-19 Developer (Kodak) the autoradiograms were quantitatively analyzed by computer-assisted densitometry (RAS-3000, Amersham). A full report of the autoradiographic quantitation of the injection spread has been published elsewhere (29).

Measurement of organ blood flow. The rats were anesthetized with ketamine-acepromazine, and a guide cannula for injections into POM was placed on the skull as described above. A midline laparotomy was then made, and the left renal and superior mesenteric arteries and lower abdominal aorta above its bifurcation were carefully isolated under a dissecting microscope. Doppler flow probes (Valpey-Fisher, Hopkinton, MA) were then loosely sutured around each vessel as earlier described $(11,26)$. The insulated wire leads were fixed to the back muscles, tunneled under the back skin to exit at the neck, and soldered to a receptacle that was then attached to the skull with small srews and dental acrylic. The animals were allowed to recover from the surgery for 7 days. Twenty-four hours before the experiment, the rat was reanesthetized with halothane ( $2 \%$ in oxygen), and the femoral artery and vein were catheterized with PE-50 tubing. The catheters were tunneled under the back skin, exited at the nape of the neck, and secured by a soft spring wire.

On the day of the experiment, the arterial catheter was connected to a pressure transducer (Narco), and blood pressure and heart rate were continuously recorded on the Narcotrace 80 physiograph. A cable connecting the blood flow receptacle and the Doppler flowmeter (University of Iowa, Bioengineering Facility, model no. 545C4) was attached to the animal, and the mean blood flow was continuously recorded on the physiograph. Vascular resistance was calculated by dividing the mean arterial pressure by blood velocity (Doppler shift in $\mathrm{kHz}$ ) as described earlier $(11,26)$. Changes in blood flow and vascular resistance are expressed as a percent of control values.

Recording of renal sympathetic nerve activity. In a separate group of rats, efferent renal sympathetic nerve activity was recorded simultaneously with renal blood flow and mean arterial pressure in chloralose-anesthetized rats. Polyethylene catheters (PE-50) were inserted into the left femoral artery and vein under halothane ( $2 \%$ in oxygen) anesthesia. Thereafter, the anesthesia was continued with intravenous infusion of chloralose $(150 \mathrm{mg} / \mathrm{kg})$, and the trachea was cannulated. The rats were placed on a stereotaxic device (DKI), and a 30 gauge needle was inserted into the POM. Through a left flank incision, the left kidney and its blood vessels were exposed, and a renal nerve branch was carefully dissected from the aorticorenal junction. A Doppler flow probe was then placed around the left renal artery, with care being taken not to damage the renal nerves. The isolated nerve branch was then placed on a bipolar Teflon-coated platinum hook electrode and was protected by a pool of warm mineral oil. The body temperature was kept at $37^{\circ} \mathrm{C}$ by means of an Aquamatik heating pad. The animal was artificially ventilated (Harvard Rodent Respirator) with $100 \%$ oxygen and with respiratory muscles paralyzed with gallamine $(20 \mathrm{mg} / \mathrm{kg}$ iv). The nerve signal was amplified 50,000 times by a Grass P511 band pass amplifier at a band pass of $30-3,000 \mathrm{~Hz}$. The amplified and filtered signal was rectified and integrated by a Buxco cardiovascular analyzer operated by an IBM personal computer and was stored together with the blood pressure and blood flow data on floppy discs. The signal was also channeled to a Tektronix 5113 oscilloscope for visual evaluation, to Grass audio amplifier for auditory evaluation, and through a rectifying voltage integrator (Narco type $730 \mathrm{M}$ ) to the physiograph. The rectified integrated nerve signal was continuously displayed together with the arterial pressure and renal blood flow on the Narcotrace physiograph. At the end of the experiment, the nerve was cut proximal to the recording electrode, and the electrical noise that remained after nerve section was recorded and processed as the nerve signal. The magni- 
tude of this noise was considered to be an estimate of "zero" nerve activity, and it was subtracted from previously recorded activity to obtain true estimates of sympathetic activity.

Assay of plasma catecholamines. Blood samples $(0.8$ $\mathrm{ml}$ ) were withdrawn from the arterial catheter $30 \mathrm{~min}$ after the administration of TRH. The blood withdrawn was replaced with an equal volume of fresh rat blood. The blood specimens were collected in chilled test tubes, centrifuged (Beckman microfuge B) for $1 \mathrm{~min}$, and the plasma was removed and rapidly frozen on dry ice. Epinephrine and norepinephrine were separated by alumina extraction and were assayed by high-performance liquid chromatography with electrochemical detection (6).

Drugs used. The following drugs were used. TRH, Lglutamic acid, sodium salt, L-epinephrine, and L-norepinephrine were from Sigma. Sodium nitroprusside was from Ciba. The glutamate NMDA receptor blocker MK801 (14) was kindly provided by Merck Sharpe \& Dohme. All drugs were dissolved in $0.9 \% \mathrm{NaCl}$ (saline).

Statistical analysis of data. Data in text and Figs. 1-7 are means $\pm \mathrm{SE}$ for the given number of rats. The doseresponse and time-response relationships were analyzed by one-way analysis of variance with the Student-Newman-Keuls test; the differences in plasma catecholamine levels before and after TRH or glutamate administration and the magnitude of TRH or glutamate responses before and after MK-801 treatment were assessed by the paired Student's $t$ test and the nonparametric two-tailed Wilcoxon matched-pairs test for data with unequal variances.

\section{RESULTS}

Histology and injection spread. More than $75 \%$ of the radioactivity after the 50-nl injection was found within a diameter of $600 \mu \mathrm{m}$ from the injection site (Fig. 1). Sixteen out of 24 glutamate injections and 12 out of 25 TRH injections were localized in the POM area below the anterior commissure, $0.3-0.8 \mathrm{~mm}$ left from the third ventricle. Six glutamate injections and seven TRH injections were found in the POMn in the midline structure above the third ventricle. Hemodynamic responses to TRH and glutamate in POM and POMn were identical. In one rat, injection of TRH into the supraoptic nucleus induced strong pressor $(+33 \mathrm{mmHg})$, tachycardic $(+158$ beats/min), hindquarter vasodilator, and mesenteric as well as renal vasoconstrictor responses, whereas injections into the lateral preoptic area (2 rats) or into the anterior hypothalamus (1 rat) increased blood pressure and heart rate without affecting the regional blood flow.

Effects of TRH in conscious rats. Microinjections of TRH into the POM or POMn increased blood pressure, heart rate, hindquarter blood flow, and decreased blood flow in the splanchnic organs (Fig. 2). Peak cardiovascular changes were reached $30 \mathrm{~s}-3$ min after the injection and subsided in 5-10 min. Mean arterial pressure and heart rate were significantly increased by all doses of TRH (Fig. 3). The doses of 24 and 240 pmol increased hindquarter blood flow by $+37 \pm 9 \%(P<0.01)$ and +61 $\pm 18 \%(P<0.01)$, respectively. The increase in flow was the result of a significant reduction in hindquarter vas-
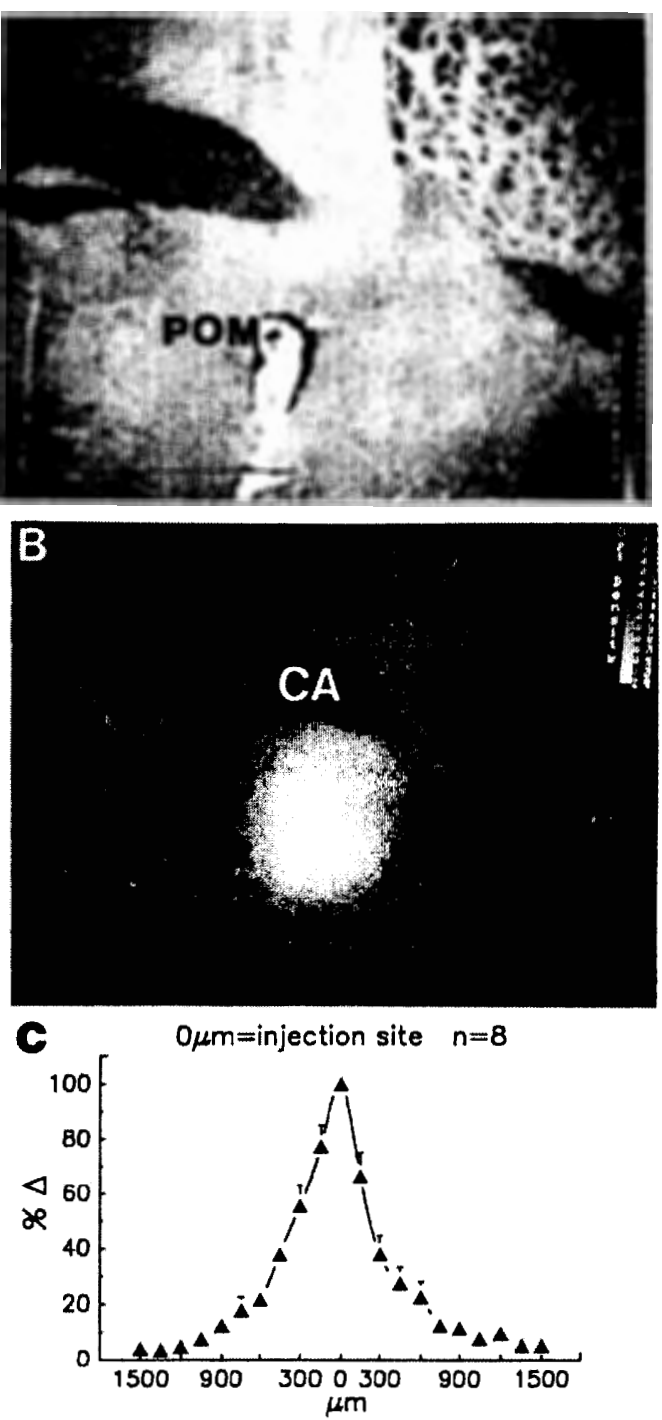

FIG. 1. Spread of radioactivity after injection of $50-\mathrm{nl}$ volume of [ $\left.{ }^{3} \mathrm{H}\right]\left[3\right.$-methyl-His ${ }^{2}$ thyrotropin-releasing hormone (TRH) into medial preoptic nucleus (POM). $A$ and $B$ : coronal section through forebrain demonstrating injection site in POM. $A$ : thionine-stained section (50 $\mu \mathrm{m}) . B$ : dark field autoradiogram of adjacent slide $(10 \mu \mathrm{m})$. Landmarks include chiasma opticum, commissura anterior, and fornix, scale $1 \mathrm{~mm}$. $C$ : anteroposterior distribution of $\left[{ }^{3} \mathrm{H}\right]\left[3\right.$-methyl-His $\left.{ }^{2}\right] \mathrm{TRH}(50 \mathrm{nl}$ of $15 \mu \mathrm{M}$ solution) from injection site.

cular resistance, $-21 \pm 6 \%(P<0.05)$ and $-32 \pm 9 \%(P$ $<0.05$ ), respectively (Fig. 3 ). In contrast to the hindquarter response to TRH, mesenteric blood flow after the 24- and 240-pmol doses of TRH was reduced by -16 $\pm 2 \%(P<0.05)$ and $-23 \pm 7 \%(P<0.05)$, respectively. Corresponding changes in mesenteric resistance were $+31 \pm 6 \%(P<0.05)$ and $+43 \pm 16 \%(P<0.05)$ (Fig. 3). Renal blood flow, however, was not significantly altered by $\mathrm{TRH}$, whereas the renal resistance tended to increase (Fig. 3).

Plasma samples for catecholamines were collected after the 24-pmol/kg dose of TRH in some of the rats ( $n$ $=6$ ). In accord with our previous data $(7,26)$, a stimulation of the sympathetic nervous system and adrenal medulla was apparent as the plasma epinephrine levels were increased by $200 \%$ and plasma norepinephrine content by $58 \%$ at the peak of the pressor response $3 \mathrm{~min}$ 


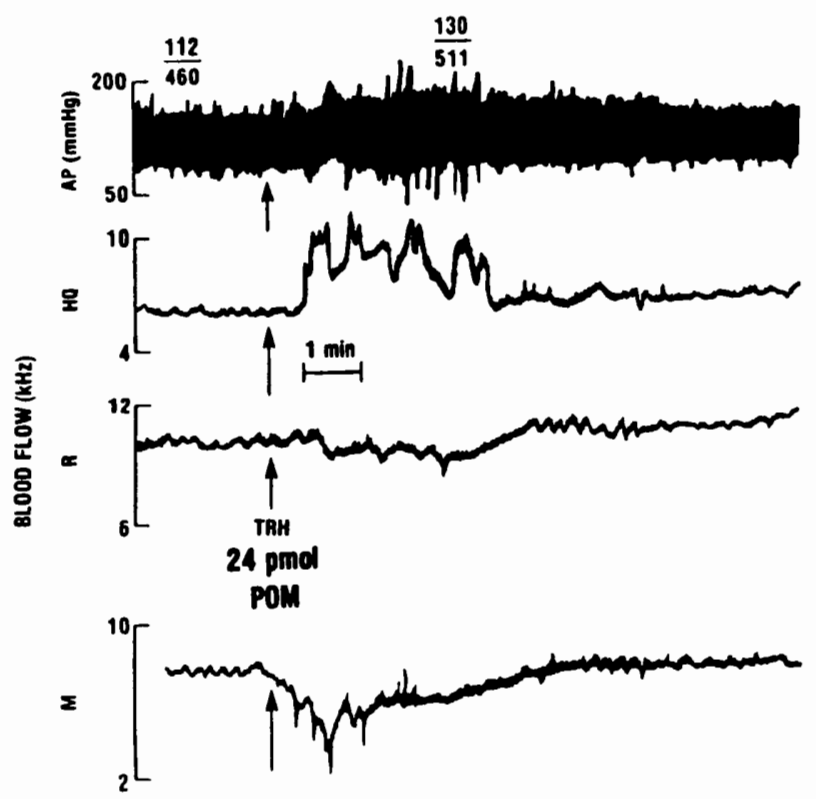

FIG. 2. Representative tracing of arterial pressure (AP) and regional blood flow changes after intraparenchymal injection of TRH (24 pmol/ $50 \mathrm{nl}$ ) into POM. HQ, hindquarter; $M$, mesenteric; $R$, renal.

after TRH administration (Table 1).

Effect of TRH on sympathetic nerve activity in anesthetized rats. In the anesthetized rat, TRH $(2.4 \mathrm{pmol})$ significantly increased renal sympathetic nerve activity (Fig. 4). Nerve activity was increased within seconds after TRH administration and subsided within 15-20 min. Systemic arterial pressure or renal blood flow was not changed by this dose of TRH.

Effects of glutamate in conscious rats. In conscious rats, glutamate injections into the POM or POMn induced the defense response pattern of hemodynamic changes (Fig. 5). Peak cardiovascular changes were reached 30 $60 \mathrm{~s}$ after the injection and subsided in 1-5 min. The 10nmol dose produced hindquarter vasodilation with simultaneous mesenteric vasoconstriction with no significant effect on the other cardiovascular variables (Fig. 6). Mean arterial pressure and heart rate were significantly increased by the 100-nmol dose of glutamate (Fig. 6). At this dose, glutamate increased hindquarter blood flow $(+48 \pm 8 \%, P<0.05)$ due to decreased hindquarter vascular resistance $(-31 \pm 3 \%, P<0.01)$ (Fig. 6). Blood flow in mesenteric and renal vascular beds were decreased by $-33 \pm 6 \%(P<0.05)$ and by $-19 \pm 4 \%(P<$ $0.05)$, respectively. Corresponding increases in mesenteric and renal vascular resistance were $+87 \pm 22 \%$ ( $P$ $<0.05)$ and $+29 \pm 9(P<0.05)$, respectively (Fig. 6).

Stimulation of the sympathetic nervous system and adrenal medulla by the $100-\mathrm{nmol}$ dose of glutamate was manifested by increased levels of plasma epinephrine $(+90 \%$ from baseline) and norepinephrine $(+48 \%$ from baseline) in samples collected at the peak of the pressor response (Table 1 ).

Influence of MK-801 on hemodynamic responses to TRH and glutamate. Injection of MK-801 $(300 \mu \mathrm{g} / \mathrm{kg}$ iv) in the conscious rat tended to increase blood pressure and heart rate but had no statistically significant hemodynamic effects (Table 2). The hemodynamic variables were not different from control before TRH or glutamate
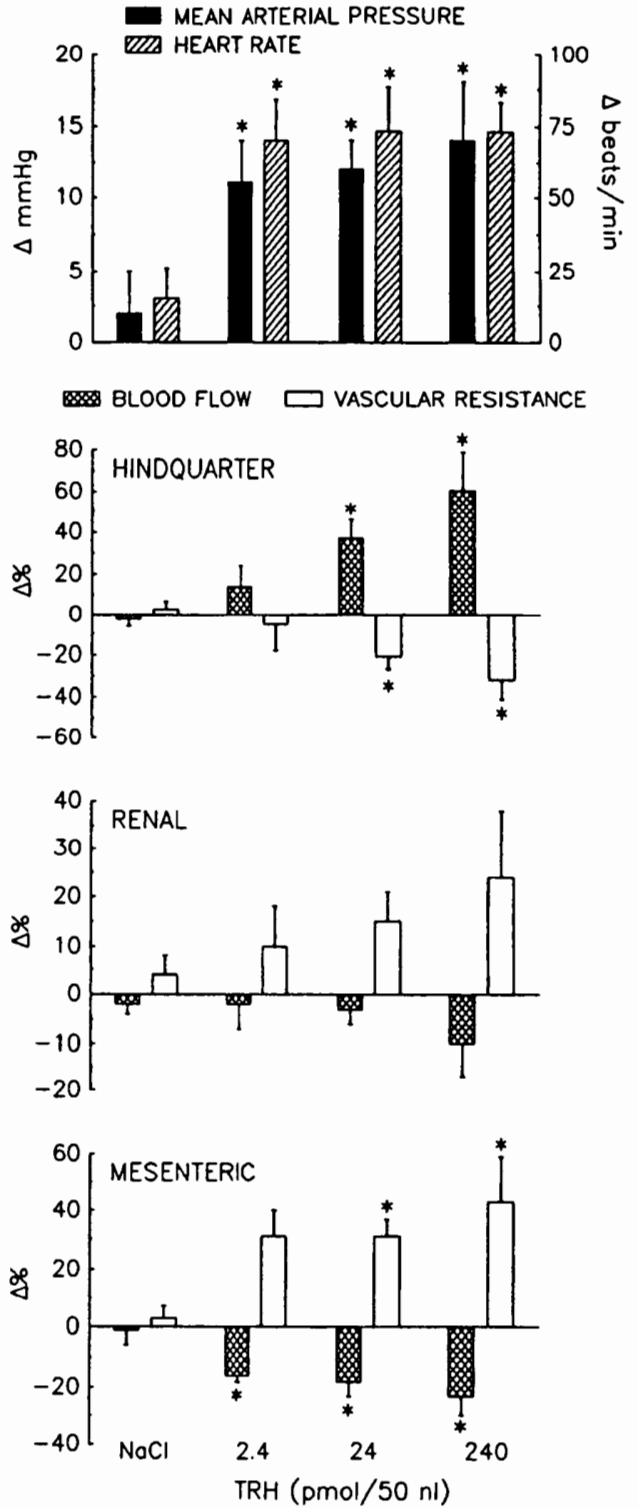

FIG. 3. Effect of TRH on mean arterial pressure, heart rate, regional blood flow, and vascular resistance in conscious rat. Saline or TRH (50 $\mathrm{nl}$ ) at doses of $2.4,24$, or $240 \mathrm{pmol} / 50 \mathrm{nl}$ was injected into POM. Values (means $\pm \mathrm{SE}$ ) represent maximum changes $30 \mathrm{~s}-3 \mathrm{~min}$ after injection. No. of animals $(n)$ in saline group is 8 , in $2.4 \mathrm{pmol}$ group $n=6$ (except for renal blood flow and resistance in which $n=5$ ), in $24 \mathrm{pmol}$ group $n=18$ (except for renal blood flow and resistance in which $n=15$ ), and in 240 pmol group $n=5$ (except for renal blood flow and resistance in which $n=4) .{ }^{*} P<0.05$, statistical significance from saline group by Student-Newman-Keuls test.

\section{administration.}

Pressor and tachycardic responses to TRH (24 pmol) were completely abolished after MK-801 treatment, whereas the regional hemodynamic changes were not affected (Fig. 7). After MK-801 treatment, glutamate had no significant effect on mean arterial pressure or heart rate (Fig. 7). MK-801 significantly attenuated the decrease in mesenteric blood flow $(-42 \pm 10 \%$ before MK-801, $-25+10 \%$ after MK-801, $P<0.05$ by paired $t$ test) and the increase in mesenteric vascular resistance $(+118 \pm 44 \%$ before MK-801, $+47 \pm 23 \%$ after MK-801, $P=0.011$ by Wilcoxon matched-pairs test). 
TABLE 1. Effect of TRH and glutamate on plasma levels of epinephrine and norepinephrine after administration into hypothalamic medial preoptic nucleus in conscious rat

\begin{tabular}{lll}
\hline \hline Plasma Level, pg/ml & Baseline & Peak \\
\hline TRH $(n=4)$ & & \\
Epi & $190 \pm 47$ & $648 \pm 135^{*}$ \\
NE & $208 \pm 19$ & $329 \pm 45^{*}$ \\
Glutamate $(n=5)$ & & \\
Epi & $133 \pm 18$ & $253 \pm 16^{*}$ \\
NE & $147 \pm 14$ & $218 \pm 28^{*}$ \\
\hline
\end{tabular}

Values are means $\pm \mathrm{SE}$ and indicate catecholamine levels at control and during peak of pressor response to glutamate; $n$, no. of rats. TRH, thyrotropin-releasing hormone (24 pmol/50 nl); Epi, epinephrine; $\mathrm{NE}$, norepinephrine. Glutamate was used in a dose of $100 \mathrm{nmol} / 50 \mathrm{nl} .{ }^{*} P$ $<0.05$ vs. control, statistical significance between baseline and peak values by paired Student's $t$ test.

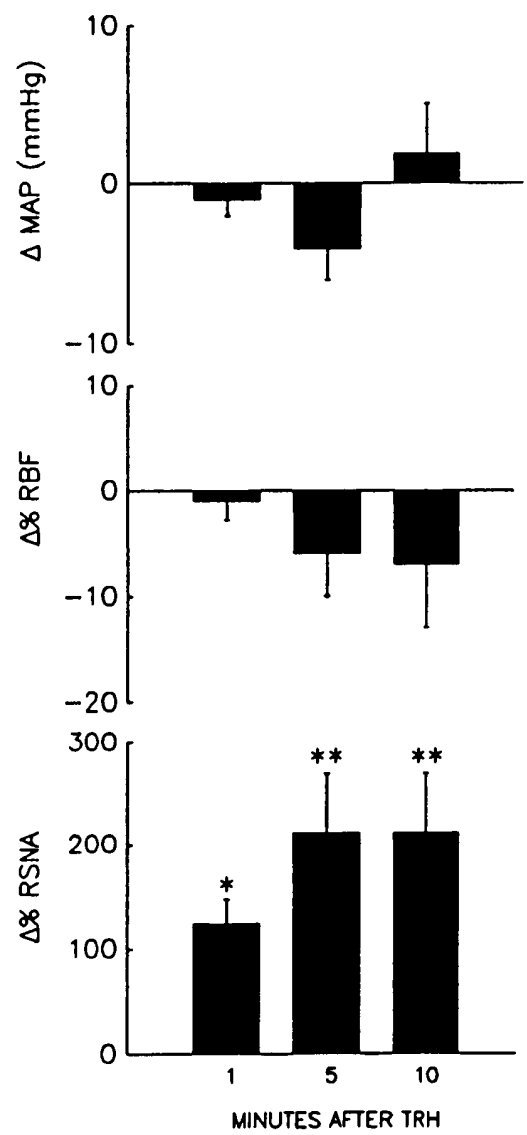

FIG. 4. Effect of TRH on mean arterial pressure (MAP), renal blood flow (RBF), and renal sympathetic nerve activity (RSNA) in chloralose-anesthetized rat. Values (means $\pm \mathrm{SE}$ ) denote changes 1,5 , and $10 \mathrm{~min}$ after microinjection of TRH $(2.4 \mathrm{pmol} / 50 \mathrm{nl})$ into POM. No. of animals is 5 at each time point. ${ }^{*} P<0.05$ and ${ }^{* *} P<0.01$, statistical significance from control by Student-Newman-Keuls test.

\section{DISCUSSION}

In the present study, microinjections of picomole doses of TRH into the POM of conscious rats produced the classical hemodynamic defense response $(28,30)$ characterized by increases in blood pressure and heart rate with hindquarter skeletal muscle vasodilation and splanchnic vasoconstriction. The hemodynamic changes became apparent immediately after the injection into the
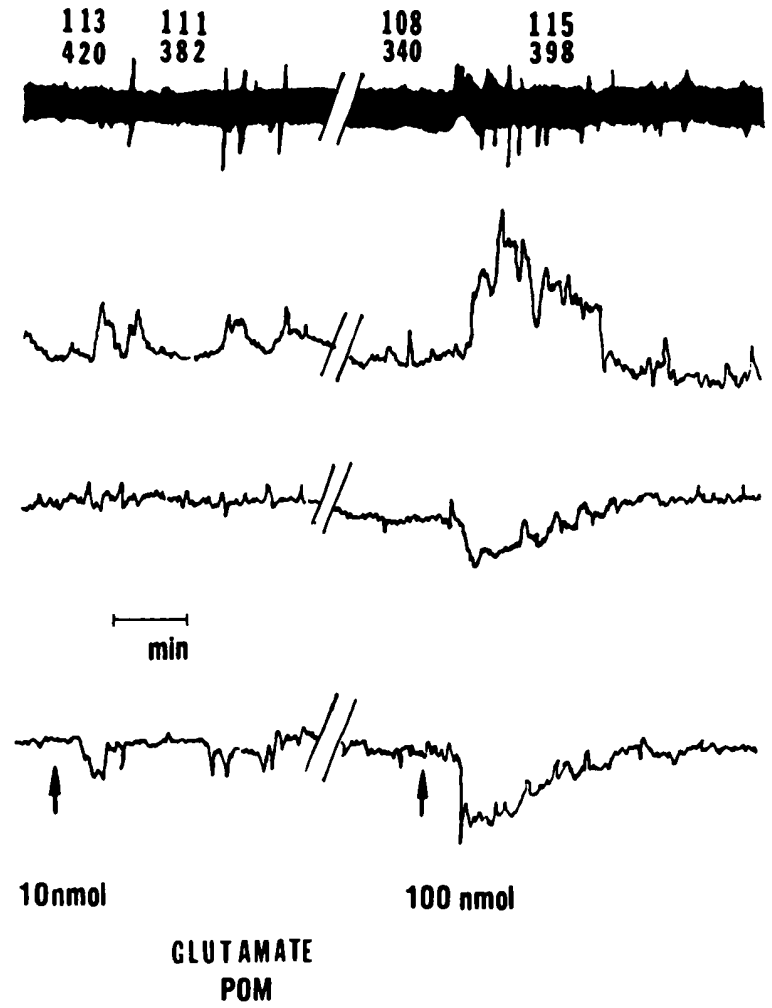

FIG. 5. Representative tracing of arterial pressure and regional blood flow changes after intraparenchymal injection of glutamate (10 $\mathrm{nmol} / 50 \mathrm{nl}$ and $100 \mathrm{nmul} / 50 \mathrm{nl}$ ) into POM.

POM, became maximal in $30 \mathrm{~s}-3 \mathrm{~min}$, and subsided in $10 \mathrm{~min}$. Almost immediate appearance of the responses suggests that the site of action for these effects lies within the POM. Previous studies pointed to an important role of the hypothalamus in mediation of TRH actions; local microinjections of a 1.4-pmol dose of TRH into the POM and preoptic suprachiasmatic nucleus evoked pressor and tachycardic responses in halothane-anesthetized rats, whereas similar injections into the anterior hypothalamic nucleus or the dorsomedial hypothalamic nucleus produced tachycardia but no change in mean arterial pressure $(5,24)$. In conscious rats, injections of TRH at nanomole range resulted in pressor and tachycardic responses that were accompanied by increased levels of plasma catecholamines (7).

Intracerebroventricular administration of picomole doses of TRH in conscious rats has been shown to produce hemodynamic responses with identical time response and magnitude as those seen after POM injections in the present study (26). Pressor and tachycardic responses were also reported after icv infusion of TRH at picomole doses in halothane-anesthetized rats (5), whereas, in the urethane-anesthetized rat, significant increments in blood pressure were seen only after nanomole doses of TRH, and the onset of the TRH effects in the urethane-anesthetized rat was significantly slower; the maximum responses were observed 15 min after the administration of TRH and were sustained for $30 \mathrm{~min}$ $(16,17)$. Interestingly, similar sustained pressor responses with slow onset were recently reported after injections of nanomole doses of TRH into the dorsal raphe nucleus (18). Because the effects elicited by TRH 

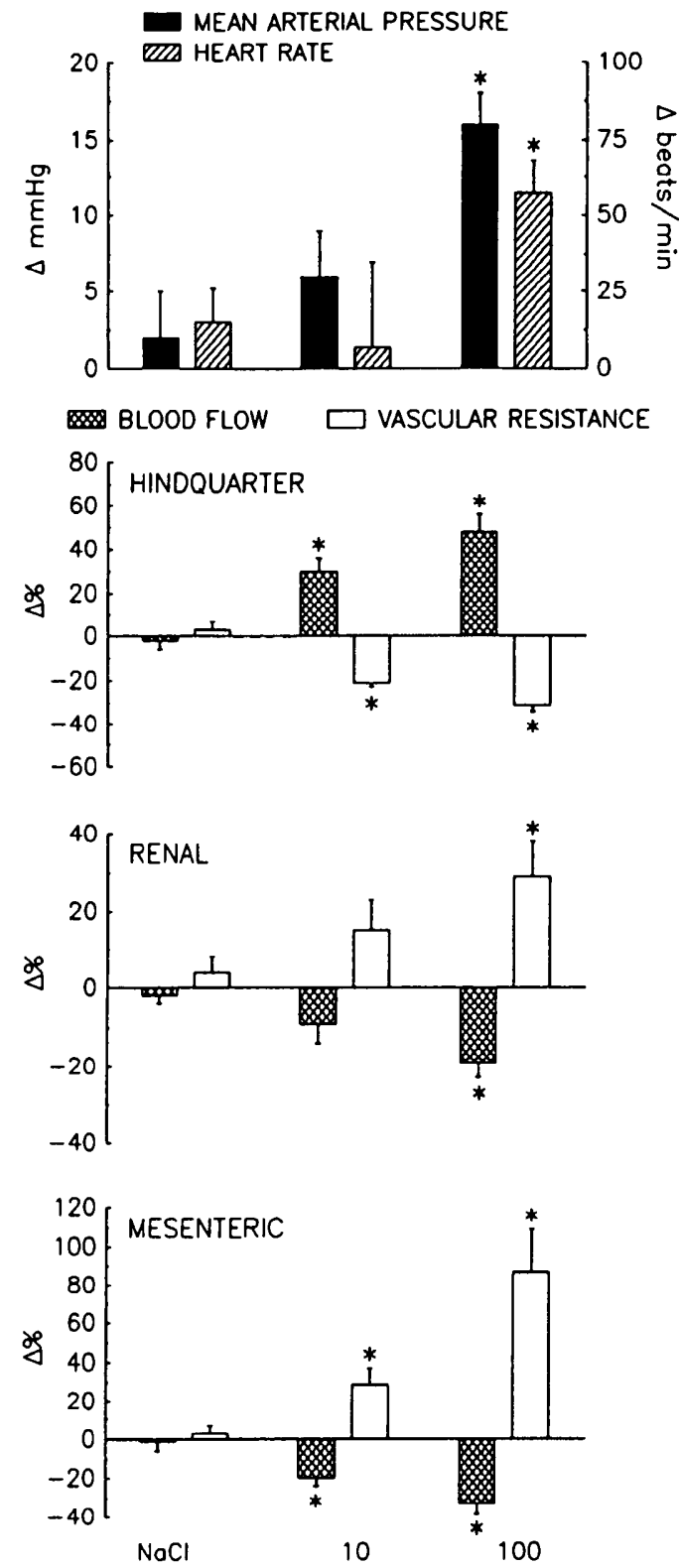

GLUTAMATE (nmol/50 $\mathrm{nl}$ )

FIG. 6. Effect of glutamate on mean arterial pressure, heart rate, regional blood flow, and vascular resistance in conscious rats. Volume of saline or glutamate $(50 \mathrm{nl})$ at doses of 10 or $100 \mathrm{nmol} / 50 \mathrm{nl}$ was injected into POM. Values (means $\pm \mathrm{SE}$ ) represent changes $30 \mathrm{~s}-2 \mathrm{~min}$ after injection. No. of animals $(n)$ in saline group is 8 ; in $10 \mathrm{nmol}$ group $n=6$, and in $100 \mathrm{nmol}$ group $n=18$ (except for renal blood flow and vascular resistance in which $n=15$ ). ${ }^{*} P<0.05$, statistical significance from saline group.

in the dorsal raphe nucleus were not attenuated by electrolytic lesions of the preoptic area or the paraventricular hypothalamic nucleus, the TRH terminals in the dorsal raphe (21) seem to constitute a neuronal circuit separate from the pathway mediating the hemodynamic and sympathetic responses elicited by microinjections of TRH into the POM and by icv injections of TRH at the picomole doses $(5,26)$.

A profound stimulation of the sympathetic nervous system appears to mediate the hemodynamic effects produced by microinjections of TRH into the POM since circulating levels of catecholamines were increased si-
TABLE 2. Effect of MK-801 on cardiovascular variables in conscious rat

\begin{tabular}{lccccc}
\hline \multirow{2}{*}{ Variable } & Baseline & \multicolumn{4}{c}{ Min After Injection } \\
\cline { 3 - 6 } & & 1 & 5 & 10 & 30 \\
\hline$\Delta \mathrm{MAP}, \mathrm{mmHg}$ & $118 \pm 6$ & $+3 \pm 2$ & $+19 \pm 8$ & $+25 \pm 9$ & $+19 \pm 11$ \\
$\Delta$ HR, beats/min & $392 \pm 20$ & $+5 \pm 10$ & $+25 \pm 15$ & $+50 \pm 39$ & $+57 \pm 13$ \\
$\% \Delta$ HQVR & $23 \pm 3^{*}$ & $-3 \pm 6$ & $+5 \pm 4$ & $+14 \pm 5$ & $+47 \pm 37$ \\
$\% \Delta \mathrm{MVR}$ & $14 \pm 1^{*}$ & $+3 \pm 2$ & $+8 \pm 6$ & $+17 \pm 7$ & $+29 \pm 11$ \\
$\% \Delta \mathrm{RVR}$ & $15 \pm 1^{*}$ & $+8 \pm 2$ & $+9 \pm 3$ & $+19 \pm 9$ & $+23 \pm 10$ \\
\hline
\end{tabular}

Values are means $\pm \mathrm{SE}$. $\triangle \mathrm{MAP}$, change in mean arterial pressure; $\triangle \mathrm{HR}$, change in heart rate; \% $\triangle \mathrm{HQVR}, \%$ change in hindquarter resistance; $\Delta \% \mathrm{MVR}, \%$ change in mesenteric resistance; $\Delta \% \mathrm{RVR}, \%$ change in renal resistance. MK-801 was injected intravenously at a dose of 300 $\mu \mathrm{g} / \mathrm{kg} .{ }^{*} \mathrm{mmHg} / \mathrm{kHz} ; n=5-7$.

$$
\begin{aligned}
& \text { TRH TRH } \\
& \text { TRH AFTER MK-801 GLUTAMATE (GLU) }
\end{aligned}
$$
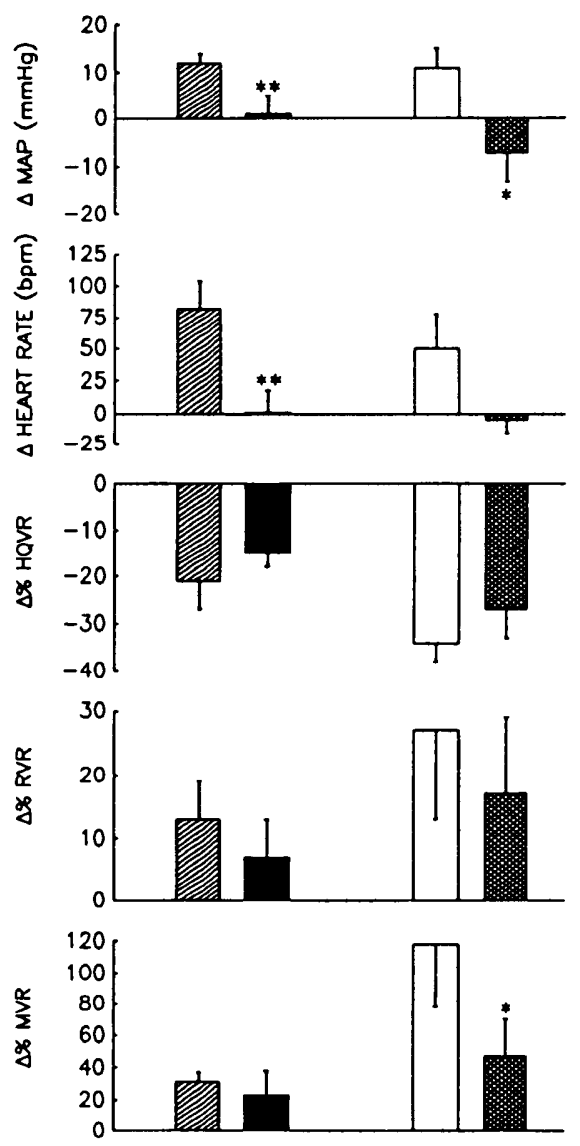

FIG. 7. Influence of $N$-methyl-D-aspartate-receptor antagonist MK801 on hemodynamic responses elicited by TRH or glutamate in POM. MK-801 (300 $\mu \mathrm{g} / \mathrm{kg}$ iv) was injected $20 \mathrm{~min}$ before POM injection of TRH or glutamate was repeated. Values (means \pm SE) represent maximum changes after POM injection of TRH or glutamate. No. of animals $(n)$ in TRH groups is 10 , in glutamate groups $n=9 .^{*} P<0.05$ and ${ }^{* *} P<0.01$, statistical difference between changes before and after MK-801 administration in each treatment group (TRH or glutamate) by paired Student's $t$ test or by Wilcoxon matched-pairs test (for mesenteric vascular resistance). $\triangle \% \mathrm{HQVR}$, change in hindquarter resistance; $\Delta \% \mathrm{RVR}$, change in renal resistance; $\Delta \% \mathrm{MVR}$, change in mesenteric resistance.

multaneously with the peak of the TRH-induced cardiovascular responses. The plasma epinephrine was increased by $>200 \%$ at the peak of the TRH-induced pressor response, whereas plasma norepinephrine increased by $\sim 50 \%$, indicating an activation of both the 
sympathetic nerves and adrenal medulla. The magnitude of the increase in plasma norepinephrine was about fourfold less than the rise of plasma epinephrine, suggesting a preferential activation of the adrenal medulla, but the rapid clearance of released neurotransmitter by the sympathetic nerves could also explain this difference. Indeed, when efferent sympathetic nerve activity was directly monitored in the anesthetized rat, TRH increased sympathetic outflow by $200 \%$, even at a dose $(2.4$ pmol) that had no significant hemodynamic effects in the anesthetized rat. Again, our present data were well in agreement with the previous studies in which icv TRH produced elevations in the circulating levels of catecholamines (26) and increased efferent sympathetic nerve activity in the renal and splanchnic sympathetic nerves $(16,17)$. Furthermore, the hemodynamic responses to icv TRH were also effectively blocked by ganglionic blockers, adrenolytic drugs, and adrenergic antagonists (16, 17,26 ), whereas hypophysectomy, thyroidectomy, or treatment with arginine vasopressin or angiotensin antagonists did not abolish the TRH responses $(3,16,17$, 26).

The present study further demonstrated that chemical stimulation of the POM-POMn neurons with the excitatory amino acid glutamate produced similar hemodynamic and sympathetic responses as those seen after TRH administration. Electrical stimulation of the preoptic anterior hypothalamus has been known to evoke the hemodynamic defense response in the rat $(2,8,28,30)$. The hypothalamic origin of the increases of blood pressure and heart rate evoked by electrical stimulation was recently questioned, however, since chemical stimulation with nanomole doses $(0.15 \mathrm{M}, 5-50 \mathrm{nl})$ of DL-homocysteate in the anterior preoptic hypothalamus of urethaneanesthetized artificially ventilated rats elicited primarily transient depressor and bradycardic responses, which only in some of the animals were followed by pressor and tachycardic responses (9). Because regional hemodynamic variables were not monitored in this previous study (9) the discrete changes in organ blood flow, which are characteristic for the classical vasomotor defense response $(2,8,28,30)$, could not be detected. Our present study clearly demonstrated that microinjections of the excitatory amino acid glutamate at an equivalent dose $(0.2 \mathrm{M}, 50 \mathrm{nl})$ into the POM elicited hindquarter vasodilation and mesenteric vasoconstriction, whereas the mean arterial pressure or heart rate was not significantly increased. In fact, our findings fully agree with the study by Fink and co-workers (8), who found mesenteric vasoconstriction with a simultaneous hindquarter vasodilation after low-frequency stimulation of the POMn-POM region in anesthetized rats. Increases in blood pressure and heart rate accompanied these regional hemodynamic changes only when higher stimulation frequencies were used (8). Similarly, only the high dose of glutamate (2 $\mathrm{M}, 50 \mathrm{nl}$ ) induced systemic hemodynamic changes in our study (Fig. 6). It is also noteworthy that TRH, another chemical stimulus, induced the defense response even at 1,000 -fold lower doses $(0.048-0.48 \mathrm{mM}, 50 \mathrm{nl})$ than those needed to induce cardiovascular changes by the excitatory amino acid glutamate.

Central cholinergic mechanisms have been suggested to mediate the tachycardic effect of intrahypothalamic TRH injections $(5,24)$, although some of the visceral as well as behavioral actions of TRH have been attributed to an interference with the brain aminergic systems (1). The present study provides evidence that a glutamatergic NMDA-receptor mechanism might also be involved in mediation of the pressor and tachycardic responses to TRH in the POM, since the selective NMDA-receptor antagonist MK-801 (14) blocked the pressor and tachycardic responses to TRH. The other responses were not significantly affected, however. This implies that the changes in blood pressure and heart rate may involve an NMDA-receptor-mediated mechanism, whereas it would not be case for the regional hemodynamic effects. In our previous studies (26), we have shown that an increased cardiac output is the major contributing factor for the TRH-induced pressor response, whereas total peripheral resistance does not significantly change due to the differential pattern of blood flow responses. In this respect, the responses of TRH and glutamate were somewhat different since the NMDA antagonist was able to attenuate in part the mesenteric vasoconstrictor response to glutamate. Moreover, the magnitude of the mesenteric vasoconstrictor response after the $100 \mathrm{nmol}$ dose of glutamate was much more than that produced by the 24 pmol dose of TRH (Figs. 3, 6, and 7), although the pressor responses to these doses of glutamate and TRH were almost identical. Therefore, peripheral vasoconstriction might contribute to the pressor response after glutamate injections to a much greater degree than to the TRHinduced increase in blood pressure, which is mostly dependent on the cardiac output (26).

Because the glutamate antagonist was administered intravenously, the site of the TRH-glutamate interaction cannot be determined. Although the fact that the responses induced by glutamate microinjections in the POM were qualitatively similar to those induced by TRH might support an interaction at the level of the POM, other possibilities could exist, since glutamatergic NMDA receptors are present in many cardiovascular nuclei (20). The lateral hypothalamus is an important link in the descending projections from the POM to the ventrolateral medulla and IML (25). Glutamate released in the lateral hypothalamus could relay the effects of TRH on neurons located within the POM to lower medullary centers and to the IML. In our preliminary studies, systemic injection of TRH increased glutamate and aspartate release in the lateral hypothalamus, as measured by in vivo microdialysis, whereas microinjections of glutamate into the lateral hypothalamus induced a strong pressor effect in the conscious rat. Direct anatomic proof of descending glutamatergic projections from the POM to lateral hypothalamus has not been conclusively established to date, however. Moreover, the NTS and the ventrolateral medulla are known sites for NMDA-receptor-mediated effects $(10,27)$. Because studies demonstrated an efferent TRH pathway from the ventrolateral medulla to the IML $(12,13)$ and to the NTS $(21)$, the TRH effects might be inhibited through a glutamatergic mechanism at the medullary site. Inhibition of cardiovascular responses by the NMDA-receptor antagonist might not be specific for TRH only, however, since most 
pressor responses originating from the hypothalamus would most likely be inhibited by a NMDA-receptor blocker at the level of the medulla.

In summary, the present study demonstrates that TRH and glutamate in the POM produce cardiovascular responses identical to the stress-evoked defense response. Our results complement the previous studies that demonstrate that the defense response can be evoked by electrical stimulation of the POM $(2,8,28,30)$, emphasizing its origin from neurons located within this nucleus. The present study further proposes TRH and glutamate as important neurotransmitters involved in mediating this autonomic response.

We thank Dr. David S. Goldstein for help in the catecholamine assay and Rhoda Press for excellent technical assistance.

This work was supported in part by Uniformed Services University of the Health Sciences Protocol no. R09232 to A.-L. Siren.

The opinions or assertions contained herein are the private ones of the authors and are not to be construed as official or as necessarily reflecting the views of the Department of Defense or the Uniformed Services University of the Health Sciences. The experiments reported herein were conducted according to the principles set forth in the "Guide for Care and Use of Laboratory Animals," Institute of Laboratory Animal Resources, National Research Council (Department of Health, Education, and Welfare publication no. NIH 85-23, 1985).

Address for reprint requests: A.-L. Sirén, Dept. of Neurology, Uniformed Services University of the Health Sciences, 4301 Jones Bridge Rd., Bethesda, MD 20814-4799.

Received 6 September 1990; accepted in final form 11 March 1991.

\section{REFERENCES}

1. Bennett, W., C. A. Marsden, K. C. F. Fone, J. V. Johnson, AND D. J. HEAL. TRH-catecholamine interactions in brain and spinal cord. Ann. N. Y. Acad. Sci. 553: 106-120, 1989.

2. BERECEK, K. H., AND M. J. BRODY. Evidence for a neurotransmitter role for epinephrine derived from adrenal medulla. Am. J. Physiol. 242 (Heart Circ. Physiol. 11): H593-H601, 1982.

3. BUÑAG, R. D., AND J. MatTila. Selective suppression of pressor and sympathetic responses to centrally infused TRH in hypothyroid rats. J. Cardiovasc. Pharmacol. 12: 51-57, 1988.

4. Chiba, T., AND Y. Murata. Afferent and efferent connections of the medial preoptic area in the rat: a WGA-HRP study. Brain Res. Bull. 14: 261-272, 1985.

5. Diz, D. I., AND D. M. JACOBowitz. Cardiovascular effects produced by injections of thyrotropin releasing hormone in specific preoptic and hypothalamic nuclei in the rat. Peptides 5: 801-808, 1984.

6. EISENhofER, G., D. S. Goldstein, R. STULL, R. J. KeISER, T. Sunderland, D. L. MuRPHY, AND I. J. KopIN. Simultaneous liquid-chromatographic determination of 3,4-dihydroxyphenylglycol, catecholamines and 3,4-dihydroxyphenylalanine in plasma, and their responses to inhibition of monoamine oxidase. Clin. Chem. 32: 2030-2033, 1986.

7. Feuerstein, G., A. H. Hassen, and A. I. Faden. TRH: cardiovascular and sympathetic modulation in brain nuclei of the rat. Peptides 4: 617-620, 1983.

8. Fink, G. D., J. Buggy, J. R. Haywood, A. K. Johnson, AND M. J. BRODY. Hemodynamic responses to electrical stimulation of areas of rat forebrain containing angiotensin on osmosensitive sites. Am. J. Physiol. 235 (Heart Circ. Physiol. 4): H445-H451, 1978.

9. Gelsema, A. J., M. J. Roe, and F. R. Calaresu. Neurally mediated cardiovascular responses to stimulation of cell bodies in the hypothalamus of the rat. Brain Res. 482:67-77, 1989.

10. GoRDON, F. J. Aortic baroreceptor reflexes are mediated by NMDA receptors in caudal ventrolateral medulla. Am. J. Physiol. 252 (Regulatory Integrative Comp. Physiol. 21): R628-R633, 1987.

11. Haywood, J. R., R. A. Shaffer, C. Fastenow, G. D. Fink, AND
M. J. BRoDy. Regional blood flow measurement with pulsed Doppler flow meter in conscious rat. Am. J. Physiol. 241 (Heart Circ. Physiol. 10): H273-H278, 1981.

12. Helke, C. J., S. C. Sayson, J. R. Keeler, and C. G. Charlton. Thyrotropin-releasing hormone-immunoreactive neurons project from the ventral medulla to the intermediolateral cell column: partial coexistence with serotonin. Brain Res. 381: 1-7, 1986.

13. HIRSCH, M. D., AND C. J. HELKE. Bulbospinal thyrotropin-releasing hormone projections to the intermediolateral cell column: a double fluorescence immunohistochemical-retrograde tracing study in the rat. Neuroscience 25: 625-637, 1988.

14. KEMP, J. A., A. C. FoSTER, AND E. H. F. WONG. Non-competitive antagonists of excitatory amino acid receptors. Trends Neurosci. 10: 294-298, 1987.

15. KONIG, J. F. R., AND R. A. KLIPPEL. The Rat Brain: A Stereotaxic Atlas of the Forebrain and Lower Parts of the Brain Stem. New York: Krieger, 1967.

16. MatTila, J., AND R. D. Buñag. Sympathomimetic pressor responses to thyrotropin-releasing hormone in rats. Am. J. Physiol. 251 (Heart Circ. Physiol. 20): H86-H92, 1986.

17. MatTila, J., AND R. D. BuÑag. Sympathetic vasoconstriction and renin secretion cause pressor responses to thyrotropin-releasing hormone in rats. J. Pharmacol Exp. Ther. 238: 232-236, 1986.

18. MatTila, J., AND R. D. BuÑag. Pressor and sympathetic responses to dorsal raphe nucleus infusions of TRH in rats. Am. J. Physiol. 258 (Regulatory Integrative Comp. Physiol. 27): R1464-R1471, 1990.

19. Merchenthaler, I., V. Csernus, C. Csontos, P. Petrusz, and B. MESS. New data on the immunocytochemical localization of thyrotropin-releasing hormone in the rat central nervous system. Am. J. Anat. 181: 359-376, 1988.

20. Monaghan, D. T., AND C. W. Cotman. Distribution of $N$-methylD-aspartate-sensitive L- $\left[{ }^{3} \mathrm{H}\right]$ glutamate-binding sites in rat brain. $J$. Neurosci. 11: 2909-2919, 1985.

21. Palkovits, M., E. Mezey, R. L. Eskay, and M. J. BRownstein. Innervation of the solitary tract and the dorsal vagal nucleus by thyrotropin-releasing hormone-containing raphe neurons. Brain Res. 373: 246-251, 1986.

22. Segerson, T. P., H. Hoefler, H. Childers, H. J. Wolfe, P. WU, I. M. D. JACKSON, AND R. M. LECHAN. Localization of thyrotropin-releasing hormone prohormone messenger ribonucleic acid in rat brain by in situ hybridization. Endocrinology 121: 98$107,1987$.

23. SHARIF, N. A., AND D. R. BURT. Limbic, hypothalamic, cortical and spinal regions are enriched in receptors for thyrotropin-releasing hormone: evidence from $\left[{ }^{3} \mathrm{H}\right]$ ultrofilm autoradiography and correlation with central effects of the tripeptide in rat brain. Neurosci. Lett. 60: 337-342, 1985.

24. Sills, M. A., AND D. M. JACOBowitz. Propranolol and methylatropine antagonize the cardiovascular effects produced by microinjection of the TRH analogue MK-771 into the preoptic suprachiasmatic nucleus. Peptides 9: 893-898, 1988.

25. Simerly, R. B., AND L. W. Swanson. Projections of the medial preoptic nucleus: a Phaseolus vulgaris leucoagglutinin anterograde tract-tracing study in the rat. J. Comp. Neurol. 270: 209-242, 1988.

26. SirÉ, A.-L., C. R. LAKE, AND G. FEUERSTEIN. Hemodynamic and neural mechanisms of action of thyrotropin releasing hormone in the rat. Circ. Res. 62: 139-154, 1988.

27. Somogyi, P., J. B. Minson, D. Morilak, I. Llewellyn-Smith, J. R. A., MCILhinNey, AND J. Chalmers. Evidence for an excitatory amino acid pathway in the brainstem and for its involvement in cardiovascular control. Brain Res. 496: 401-407, 1989.

28. SPYER, K. M. Neural mechanisms involved in cardiovascular control during affective behavior. Trends Neurosci. 12: 506-513, 1989. 29. VONHOF, S., A.-L. SIREN, AND G. FEUERSTEIN. Volume dependent
spatial distribution of microinjected thyrotropin-releasing hormone (TRH) into the medial preoptic nucleus of the rat: an autoradiographic study. Neurosci. Lett. 113: 187-192, 1990.

30. YARdLeY, C. P., AND S. M. Hilton. The hypothalamic and brainstem areas from which the cardiovascular and behavioral components of the defense reaction are elicited in the rat. J. Auton. Nerv. Syst. 15: 227-244, 1986. 